\title{
Control of Generalized Capillary Number on Immiscible Displacement Path: NMR Online and Network Simulation of Fluid Displacement Mechanism
}

Ting Zhao ${ }^{a}, b$, Xingfu Li ${ }^{a^{*}}$, Min Li $a^{a^{*}}$, Yanbing Tang ${ }^{a}$, Li Song ${ }^{a}$, Yabin Hec ${ }^{c}$, Kuanhong Xing ${ }^{d}$

( ${ }^{a}$ State Key Laboratory of Oil and Gas Reservoir Geology and Exploitation, Southwest

Petroleum University, Chengdu, China.610500; ${ }^{b}$ School of Petroleum Engineering and

Environmental Engineering, Yan 'an University, Yan 'an, China.716000;c Yanchang Oil Field Co., LTD, Yan'an, China.716000; d Baota Oil Production Plant, Yanchang Oil Field Co., LTD.,

Yan'an, China.716000)

Corresponding author. Xingfu Li; Min Li.E-mail address: hytlxf@vip.126.com

First author: Ting Zhao. E-mail address: slzhaoting@163.com

\section{Appendix A}

$$
\Delta P^{\mathrm{A}}-\Delta \mathrm{P}^{\mathrm{CA}}-\mathrm{G}=\Delta \mathrm{P}^{\mathrm{B}}-\Delta \mathrm{P}^{\mathrm{CB}}
$$

Where: $\quad \Delta P 1 \mathrm{~A}=\frac{8 \mu \mathrm{q} 1 \mathrm{LA}}{\pi \mathrm{r} 1 \mathrm{~A} 4} ; \Delta P 1 \mathrm{~B}=\frac{8 \mu \mathrm{q} 1 \mathrm{LB}}{\pi \mathrm{r} 1 \mathrm{~B} 4} ; \Delta P \mathrm{C} 1 \mathrm{~A}=\frac{2 \sigma \cos \theta}{\mathrm{r} 1 \mathrm{~A}} ; \Delta P \mathrm{C} 1 \mathrm{~B}=\frac{2 \sigma \cos \theta}{\mathrm{r} 1 \mathrm{~B}}$;

$$
\Delta P 2 \mathrm{~A}=\frac{8 \mu \mathrm{q} 2 \mathrm{LA}}{\pi \mathrm{r} 2 \mathrm{~A} 4} ; \Delta P 2 \mathrm{~B}=\frac{8 \mu \mathrm{q} 2 \mathrm{LB}}{\pi \mathrm{r} 2 \mathrm{~B} 4} ; \Delta P \mathrm{C} 2 \mathrm{~A}=\frac{2 \sigma \cos \theta}{\mathrm{r} 2 \mathrm{~A}} ; \Delta P \mathrm{C} 2 \mathrm{~B}=\frac{2 \sigma \cos \theta}{\mathrm{r} 2 \mathrm{~B}} ;
$$

we define the parameters of boundary condition as follows: $\mathrm{L}_{\mathrm{A}}=0, \mathrm{~L}_{\mathrm{B}}=\mathrm{L}, \mathrm{V}_{1 \mathrm{~A}}=\mathrm{Va}, \mathrm{V}_{1 \mathrm{~B}}=\mathrm{Vb}, \mathrm{V}_{2 \mathrm{~A}}=\mathrm{Vc}$, $\mathrm{V}_{2 \mathrm{~B}}=\mathrm{Vd}, \mathrm{r}_{1 \mathrm{a}}=\mathrm{r}_{\mathrm{a}}, \mathrm{r}_{1 \mathrm{~b}}=\mathrm{r}_{\mathrm{b}}, \mathrm{r}_{2 \mathrm{a}}=\mathrm{r}_{\mathrm{c}}, \mathrm{r}_{2 \mathrm{~b}}=\mathrm{r}_{\mathrm{d}}$. According to Eqs 1:

$$
\begin{aligned}
& \frac{8 \mu \mathrm{q} 1 \mathrm{LA}}{\pi \mathrm{r} 1 \mathrm{~A} 4}-\frac{2 \sigma \cos \theta}{\mathrm{r} 1 \mathrm{~A}}-\Delta \mathrm{\rho gL}=\frac{8 \mu \mathrm{q} 1 \mathrm{LB}}{\pi \mathrm{r} 1 \mathrm{~B} 4}-\frac{2 \sigma \cos \theta}{\mathrm{r} 1 \mathrm{~B}} \\
& C a *=\left(\frac{8 \mu \mathrm{Lq} \mathrm{q}^{1}}{2 \sigma \Pi\left(r^{\mathrm{a}}+\lambda \mathrm{L}\right)^{4} \cos \theta}+\frac{\Delta \rho \mathrm{gL}}{2 \sigma \cos \theta}\right)\left(\frac{r^{\mathrm{r}(}\left(r^{\mathrm{a}}+\lambda \mathrm{L}\right)}{\lambda \mathrm{L}}\right)
\end{aligned}
$$

The generalized capillary number $\mathrm{Ca}$ * is obtained by Eqs 3 . The Bond number $\left(B_{d}=G / P\right.$ c ; ratio of gravitational to capillary forces) is employed and the Eq. 3 can be expressed as follows:

$$
C a *=\frac{8 \mu \mathrm{ra}^{\mathrm{a}} \mathrm{q}^{1}}{\sigma \lambda_{\mathrm{I}}\left(2 r^{\mathrm{a}}+2 \lambda \mathrm{L}\right)^{3} \cos \theta}+\frac{\mathrm{B}^{\mathrm{d}}}{\lambda}
$$

Then, the pressure difference between both sides of the pores is identical. According to the fractal method of two-phase flow in unequal diameter parallel channels (Tan, 2010), The flux of the two channels can be expressed as:

$$
\begin{aligned}
& \frac{8 \mu \mathrm{q} 1 \mathrm{~L}}{\operatorname{srb} 4}+2 \sigma \cos \theta\left(\frac{1}{\mathrm{ra}}-\frac{1}{\mathrm{rb}}\right)=\frac{8 \mu \mathrm{q} 2 \mathrm{~L}}{\operatorname{srd} 4}+2 \sigma \cos \theta\left(\frac{1}{\mathrm{rc}}-\frac{1}{\mathrm{rd}}\right) \\
& \frac{8 \mu \mathrm{q} 1 \mathrm{~L}}{\operatorname{srb} 4}-\frac{8 \mu \mathrm{qL}}{\mathrm{rrd} 4}+\frac{8 \mu \mathrm{q} 1 \mathrm{~L}}{\operatorname{srd} 4}=2 \sigma \cos \theta\left(\frac{1}{\mathrm{rc}}-\frac{1}{\mathrm{rd}}-\frac{1}{\mathrm{ra}}+\frac{1}{\mathrm{rb}}\right) \\
& \frac{8 \mu \mathrm{q} 1 \mathrm{~L}}{\pi}\left(\frac{1}{\mathrm{rb} 4}+\frac{1}{\mathrm{rd} 4}\right)=2 \sigma \cos \theta\left(\frac{1}{\mathrm{rc}}-\frac{1}{\mathrm{rd}}-\frac{1}{\mathrm{ra}}+\frac{1}{\mathrm{rb}}\right)+\frac{8 \mu \mathrm{qL}}{\pi \mathrm{rd} 4} \\
& q^{1}=\left[\frac{8 \mu^{\mathrm{w}} \mathrm{Lq}}{\pi r^{\mathrm{d}} \mathrm{d}}-2 \sigma \cos \theta\left(\frac{1}{r^{\mathrm{c}}}-\frac{1}{r^{\mathrm{d}}}-\frac{1}{r^{\mathrm{a}}}+\frac{1}{r^{\mathrm{b}}}\right)\right] / \frac{8 \mu^{\mathrm{w}} \mathrm{L}}{\pi}\left(\frac{1}{r^{\mathrm{b} 4}}+\frac{1}{r^{\mathrm{d}}}\right) \\
& q^{2}=\left[\frac{8 \mu^{\mathrm{w}} \mathrm{Lq}}{\pi r^{\mathrm{d}} \mathrm{d}}+2 \sigma \cos \theta\left(\frac{1}{r^{\mathrm{c}}}-\frac{1}{r^{\mathrm{d}}}-\frac{1}{r^{\mathrm{a}}}+\frac{1}{r^{\mathrm{b}}}\right)\right] / \frac{8 \mu^{\mathrm{w} L}}{\pi}\left(\frac{1}{r^{\mathrm{b} 4}}+\frac{1}{r^{\mathrm{d}} \mathrm{d}}\right)
\end{aligned}
$$


According to the flow formula, substituting $\mathrm{q}_{1}=\mathrm{v}_{1} \pi \mathrm{r}_{\mathrm{b}}^{2}$ and $\mathrm{q}_{2}=\mathrm{v}_{2} \pi \mathrm{r}_{\mathrm{d}}^{2}$ into Eqs. (8), the ration of two flow rates in each channel can be derived as the following equation :

$$
\begin{aligned}
& \mathrm{q}_{1} / \mathrm{q}_{2}=\frac{8 \mu^{\mathrm{\omega}} \mathrm{Lq}}{\pi r^{\mathrm{d}} \mathrm{d}}-2 \sigma \cos \theta\left(\frac{1}{r^{\mathrm{c}}}-\frac{1}{r^{\mathrm{d}}}-\frac{1}{r^{\mathrm{a}}}+\frac{1}{r^{\mathrm{b}}}\right) / \frac{8 \mu^{\mathrm{\omega}} \mathrm{Lq}}{\pi r^{\mathrm{d}} \mathrm{d}}+2 \sigma \cos \theta\left(\frac{1}{r^{\mathrm{c}}}-\frac{1}{r^{\mathrm{d}}}-\frac{1}{r^{\mathrm{a}}}+\frac{1}{r^{\mathrm{b}}}\right) \\
& v^{1} / v^{2}=\frac{\frac{8 \mu w L q}{\pi r^{l a}}-2 \sigma \cos \theta\left(\frac{1}{r^{a}}-\frac{1}{r^{d}}-\frac{1}{r^{a}}+\frac{1}{r^{b}}\right)}{\frac{8 \mu w L q}{\pi r^{b s}}+2 \sigma \cos \theta\left(\frac{1}{r^{c}}-\frac{1}{r^{d}}-\frac{1}{r^{a}}+\frac{1}{r^{b}}\right)}
\end{aligned}
$$

For the ideal Viscous fingering water-flooding condition, the velocities of oil/water displacement in the two tubes are the same $\left(v_{l}=v_{2}\right)$. In this scenario, capillary pressure and viscous force have the same influence in common (Tan, 2010). Substituting the value of $v_{l} / v_{2}=1$ and Eq8, the total flux $\left(q_{o}\right)$ of the two channels can be obtained as below:

$$
q^{o}=\frac{\pi\left(n r^{a}+\lambda L\right)^{2}\left(r^{a}+\lambda L\right)^{2}}{2 \mu^{\omega} L\left(r^{a}+\lambda L\right)^{2}-\left(n r^{a}+\lambda L\right)^{2}} \sigma \cos \theta\left(\frac{1}{n r^{a}}-\frac{1}{n r^{a}+\lambda L}-\frac{1}{r^{a}}+\frac{1}{r^{a}+\lambda L}\right)
$$

\begin{tabular}{|c|c|c|c|}
\hline symbol & meaning & symbol & meaning \\
\hline $\mathrm{r}_{1 \mathrm{a}}=\mathrm{r}_{\mathrm{a}}$ & The radius of the inlet end of pore $1, \mu \mathrm{m}$ & $\mathrm{q} 1$ & Fluid flow into pore $1, \mathrm{ml}$ \\
\hline $\mathrm{r} 1 \mathrm{~b}=\mathrm{rb}$ & The radius of the exit end of pore $1, \mu \mathrm{m}$ & $\mathrm{q} 2$ & The flow into pore $2, \mathrm{ml}$ \\
\hline $\mathrm{r} 2 \mathrm{a}=\mathrm{rc}$ & The radius of the inlet end of pore $2, \mu \mathrm{m}$ & $\mathrm{Bd}$ & $\begin{array}{l}\text { Bond number, Ratio of gravity to capillary } \\
\text { force }\end{array}$ \\
\hline $\mathrm{R} 2 \mathrm{~b}=\mathrm{rd}$ & The radius of the exit end of pore $2, \mu \mathrm{m}$ & $\lambda$ & Aperture gradient \\
\hline $\mathrm{V} 1 \mathrm{~A}=\mathrm{Va}$ & The velocity at the entrance of pore $1, \mathrm{ml} / \mathrm{s}$ & $\mathrm{L}_{\mathrm{A}}$ & The pore length of inlet end $\mathrm{A}$ is 0 in this paper \\
\hline $\mathrm{V} 2 \mathrm{~A}=\mathrm{Vb}$ & The velocity at the inlet end of pore $2, \mathrm{ml} / \mathrm{s}$ & $\mathrm{L}_{\mathrm{B}}$ & $\begin{array}{l}\text { The pore length of inlet end } \mathrm{B} \text {, in this paper, is } \\
\text { the pore length } \mathrm{L}\end{array}$ \\
\hline $\mathrm{q}_{0}=\mathrm{q}_{1}+\mathrm{q}_{2}$ & Total flow, the sum of the two pore flows, $\mathrm{ml}$ & $\sigma$ & Oil-water interfacial tension, $\mathrm{mN} / \mathrm{m}$ \\
\hline
\end{tabular}

Attached Table 1 Symbol names and meanings

\begin{tabular}{|c|c|c|c|c|c|}
\hline \multirow{2}{*}{ Sample No. } & \multirow{2}{*}{ pressure } & \multirow{2}{*}{ saturation status } & \multicolumn{3}{|c|}{ The volume fraction of the pores occupied by oil, $\%$} \\
\hline & & & $0.1-10 \mu \mathrm{m}$ & $10-100 \mu \mathrm{m}$ & $>100 \mu \mathrm{m}$ \\
\hline \multirow{9}{*}{ sample 1} & \multirow{3}{*}{$3 \mathrm{MPa}$} & Saturated oil & 16.23 & 70.12 & 13.65 \\
\hline & & Displacement oil & 4.5 & 79.4 & 16.1 \\
\hline & & Residual oil & 18.04 & 70.5 & 11.46 \\
\hline & \multirow{2}{*}{$10 \mathrm{MPa}$} & Saturated oil & 20.72 & 73.12 & 6.16 \\
\hline & & Displacement oil & 6.58 & 92 & 1.42 \\
\hline & \multirow{4}{*}{$15 \mathrm{MPa}$} & Residual oil & 38.1 & 48 & 13.9 \\
\hline & & Saturated oil & 19.6 & 73.5 & 6.9 \\
\hline & & Displacement oil & 6.6 & 88.3 & 5.1 \\
\hline & & Residual oil & 41.7 & 48.2 & 10.1 \\
\hline sample 2 & $3 \mathrm{MPa}$ & Saturated oil & 60.6 & 31.6 & 7.8 \\
\hline
\end{tabular}

Attached Table 2 Distribution of saturated oil, produced oil and residual oil in different pore throats 


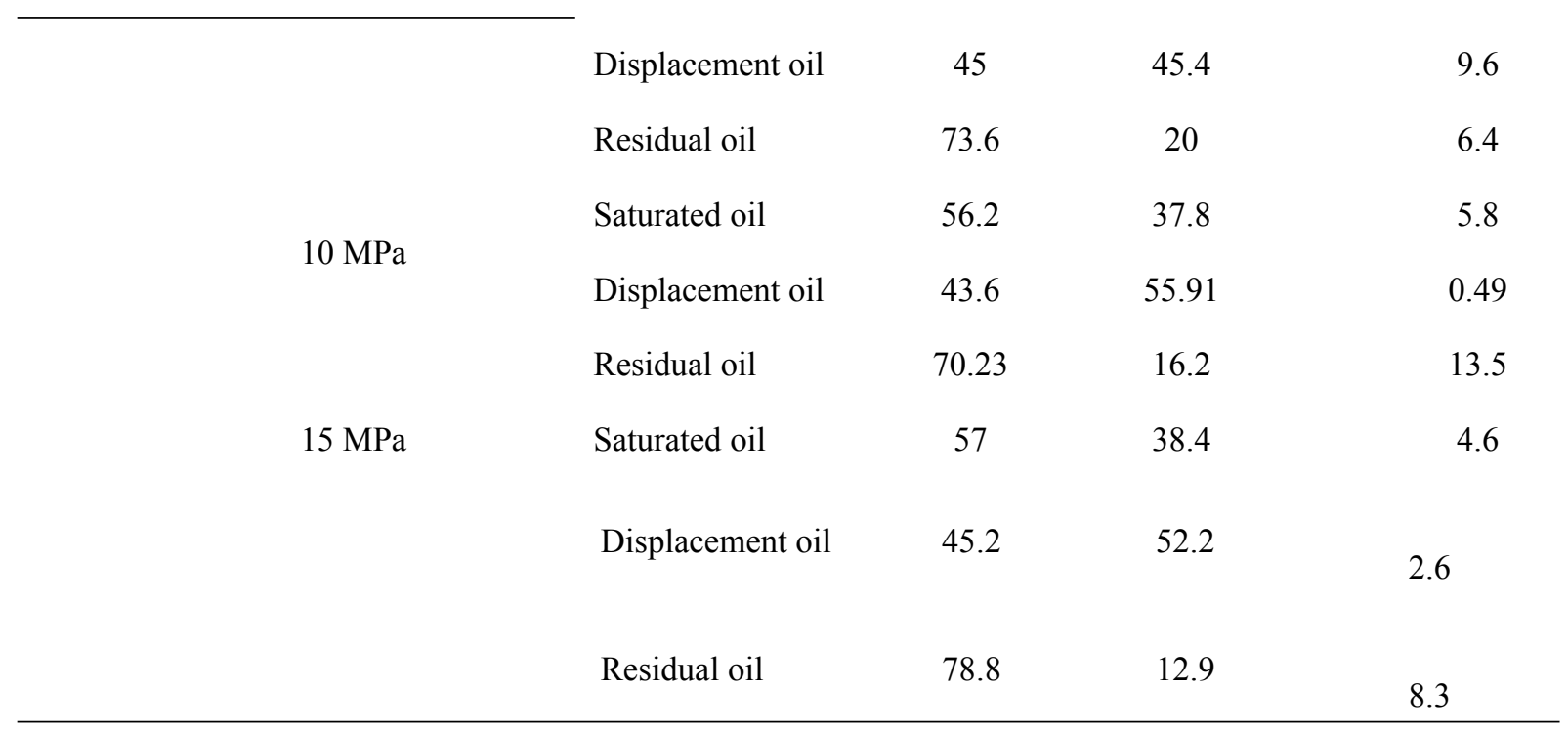

